\title{
Auditores Internos da Controladoria-Geral da União: como atuam e que INFORMAÇõES UTILIZAM ${ }^{1}$
}

Tiago Chaves Oliveira ${ }^{2}$

Wagner Brignol Menke ${ }^{3}$

\section{INTRODUÇÃO}

Nas democracias, as instituiçóes de accountability são estabelecidas para assegurar legalidade e legitimidade a governos e burocracias. No Brasil, uma das principais representantes é a Controladoria-Geral da União (CGU) (Filgueiras, 2018).

A academia registra uma série de estudos indicando que a atuação das instituições de controle gera efeitos não intencionais danosos ao governo e à sociedade (Power, 1997; Power, 2000; Campana, 2017; Nogueira e Gaetani, 2018). Em contraponto, Humphrey e Owen (2000) indicam que os citados efeitos advêm de movimento maior, relacionado com a demanda crescente por medição de desempenho na sociedade.

Olivieri (2016) concluiu que os órgãos de controle "enxugam gelo", por auditarem problemas recorrentes, "trancam portas arrombadas", por identificarem problemas quando já são muito graves, e os gestores "ficam a reboque", por se tornarem reféns dos critérios definidos pelos órgãos de controle, e tentam "correr atrás do prejuízo", saneando problemas, em vez de promover mudanças sistêmicas de prevenção de problemas.

Sobre o trabalho dos auditores internos, observa-se falta de interesse da academia (Almeida, 2013; Souza, 2017; Oliveira, 2018; Grey, 2018), o que contribui para a existência de certa "obscuridade" sobre como os auditores conduzem seu trabalho (Power, 2000; Grey, 2018, p. 83).

Adicionalmente, a atuaçáo da auditoria interna, internacionalmente e no governo federal, é lastreada na independência profissional dos auditores, ou seja, na atuação livre de interferências e das decisóes baseadas no julgamento profissional - isto é, em suas experiências e conhecimentos. Esses pressupostos são estabelecidos nas normas técnicas internacionais e nacionais que regem a profissão (IIA, 2017; CGU, 2017).

Segundo Gomide e Pires (2014), as instituiçóes de controle, atuando em seu papel de garantia da legalidade, compóem os arranjos institucionais estabelecidos para a entrega de políticas públicas. Adicionalmente, estudo sobre as capacidades do serviço federal na produção de políticas públicas registrou indícios de que as recomendaçôes de órgãos de controle são relevantes fontes de informaçôes para as políticas públicas (Enap, 2018).

Em uma perspectiva histórica, nota-se que a atuação dos auditores é dinâmica, em adaptação às necessidades e expectat. ivas de mudança da sociedade (Grey, 2018, p. 84).

1. DOl: http://dx.doi.org/10.38116/bapi24art9

2. Auditor interno da CGU.E-mail:<tiagocoliveira@gmail.com>.

3. Auditor interno da CGU.E-mail: <wagbrig@gmail.com>. 
Nesse contexto, dada a importância da atuação dos auditores, sua autonomia e os possíveis efeitos adversos, este estudo tem por objetivo analisar as atuais preferências dos auditores da CGU sobre os trabalhos que realizam e os fatores que influenciam essa decisão.

A atuação dos auditores internos governamentais no Brasil é regida pela Lei no 10.180/2001, a qual estabelece, além da função típica de realização de auditorias, a realização de apuraçóes de atos ou fatos inquinados de ilegais ou irregulares, praticados na utilização de recursos públicos federais. Segundo a Instrução Normativa (IN) no 03/2017, a função típica de auditoria divide-se em avaliação e consultoria.

\section{FIGURA 1}

\section{Formas de atuação dos auditores da CGU}

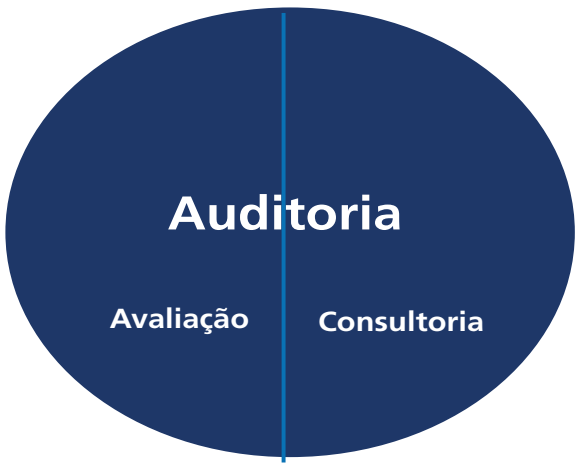

\section{Atuação didática}

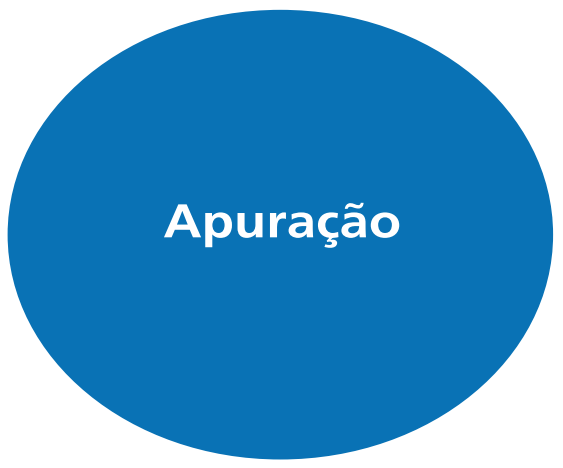

Atuação repressiva

Elaboração dos autores.

O modelo de análise deste estudo baseou-se nas conclusóes de Pires (2009), o qual examinou a atuação dos auditores fiscais do trabalho, identificando dois diferentes estilos: abordagem repressiva, exclusivamente punitiva; e abordagem pedagógica, prioritariamente educativa, orientando empresas a cumprirem a lei. Assumiu-se como pressuposto que as auditorias (avaliaçóes e consultorias) podem ser comparadas com a abordagem pedagógica, e as apuraçóes podem ser comparadas à abordagem repressiva.

Os dados foram coletados por meio de survey com amostragem probabilística, respondido por 277 dos 1.054 servidores da CGU que realizam auditorias. Além disso, foram realizadas onze entrevistas com gestores da Secretaria Federal de Controle Interno (SFC) para o entendimento das causas dos achados obtidos com o survey. Os entrevistados foram selecionados por apresentarem destacada atuação e visão abrangente da área em que atuam.

Os achados demonstram que leis, decretos e normas são as principais fontes de informação dos auditores que preferem realizar apurações. Além disso, a utilização de dados governamentais pelos auditores está mais relacionada às atuaçóes repressivas, mas também, e em menor proporção, aos trabalhos avaliativos.

\section{REFERENCIAL TEÓRICO}

A respeito das decisões tomadas no contexto das auditorias realizadas, sabe-se que a capacidade da mente humana de formular e resolver problemas complexos é muito pequena se comparada com o 
tamanho dos problemas cuja solução demanda racionalidade objetiva no mundo real (Simon, 1957, p. 198 apud Bendor, 2010, p. 2).

Olsen e Gold (2018) realizaram uma extensa revisão de literatura sobre o ceticismo profissional dos auditores e indicaram que ele pode ser afetado por emoçóes, humor, personalidade, percepçóes do auditor a respeito do auditado, experiência profissional, entre outros.

Outro aspecto importante que pode afetar as decisóes dos auditores é a sua relação com os auditados. Sobre esse aspecto, Arantes (2016) indicou que são variáveis importantes a intensidade do contato, a maturidade do órgão auditado e o escopo das açóes realizadas.

\section{METODOLOGIA}

Este estudo foi desenhado a partir da seguinte questão: como preferem atuar os auditores da CGU, de forma didática ou repressiva?

Buscou-se, também, identificar os fatores que podem influenciar a decisão dos auditores sobre como atuar e as principais fontes de informaçóes utilizadas.

Para responder à questão, a obtenção dos dados se dividiu em duas etapas: primeiro, aplicou-se um survey eletrônico com questóes definidas a partir do referencial teórico, para avaliação quantitativa das respostas; e, em seguida, foram realizadas entrevistas com gestores da SFC para se aprofundar o entendimento sobre os principais fatores que influenciam as decisóes.

A população total dos servidores que realizaram auditorias, de janeiro de 2018 a julho de 2019, é de 1.054. A partir do desenho da pesquisa e da população, foram sorteados 564 servidores por amostragem aleatória simples. Destes, 277 responderam completamente ao questionário, o que representa uma taxa de $49 \%$ de resposta.

Os entrevistados foram definidos em função de seu perfil e por apresentarem destacada atuação e visão abrangente da área em que trabalham.

QUADRO 1

Amostra das entrevistas

\begin{tabular}{|l|l|c|c|}
\hline \multicolumn{1}{|c|}{ Perfil } & \multicolumn{1}{|c|}{ Descrição } & População & Amostra \\
\hline Colegiado & Secretários (secretário e adjunto) e diretores da SFC & 8 & 4 \\
\hline Policymakers & Médio escalão do Gabinete da SFC & 4 & 2 \\
\hline Médio escalão & Coordenadores-gerais de auditoria da SFC e superintendentes regionais da CGU & 47 & 5 \\
\hline
\end{tabular}

Elaboração dos autores.

Para a avaliação dos efeitos da utilização de bases de dados nas preferências dos auditores, foi elaborado o índice de utilizaçáo das bases de dados (IBD), estruturado a partir das respostas ao survey sobre as bases utilizadas pelos respondentes nos dois últimos anos. Utilizaram-se técnicas de análise fatorial para dados categóricos (Multiple Correspondence Analysis - MCA) para resumir 51 variáveis relativas às diferentes bases de dados disponibilizadas à seleção. 


\section{GRÁFICO 1}

Curvas de probabilidade de utilização das nove bases mais utilizadas
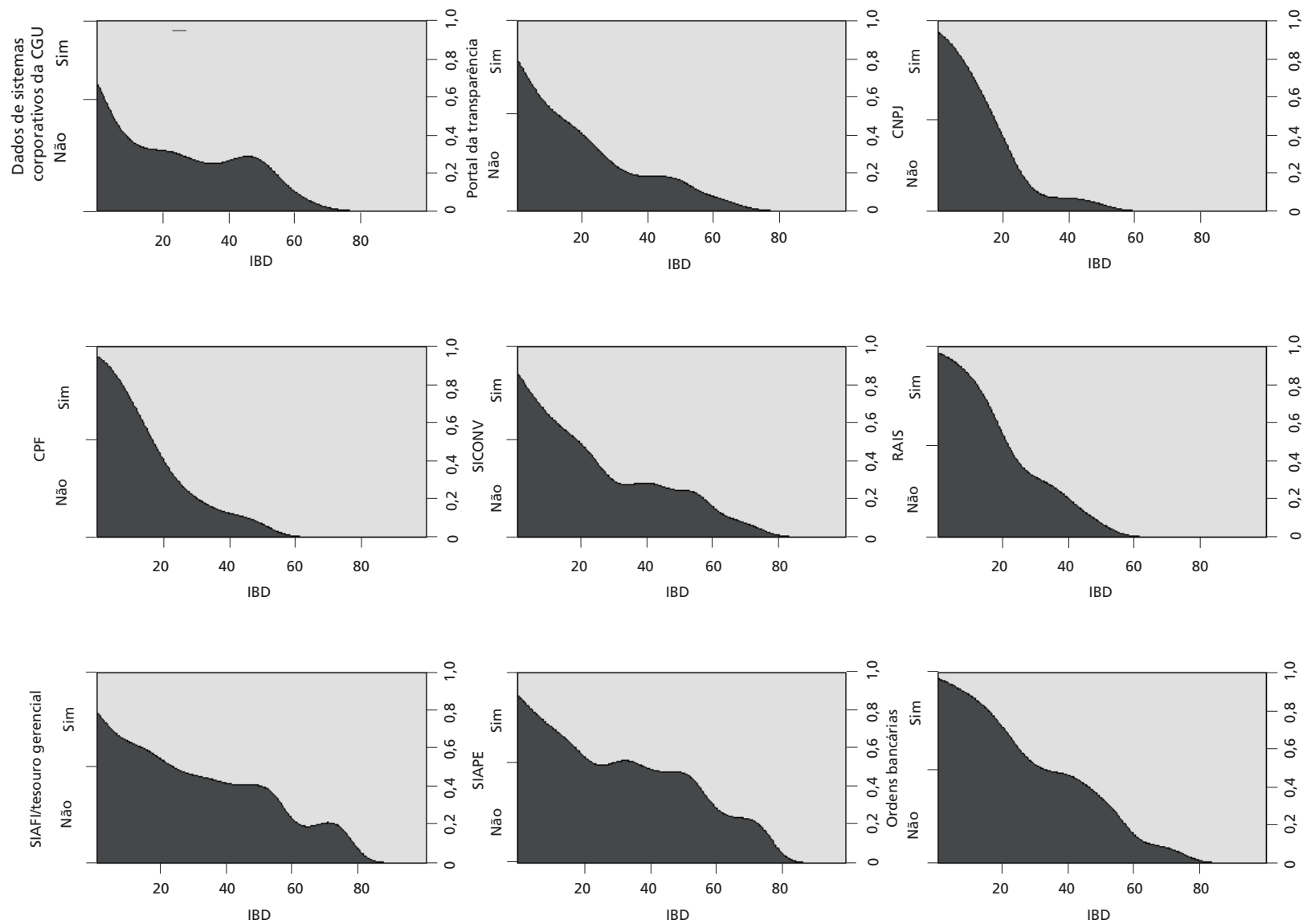

Elaboração dos autores.

Obs.: Mostra o comportamento das curvas de probabilidade de utilização das principais bases utilizadas à medida que o IBD aumenta.

Para a análise do grau de importância das diversas fontes de informaçóes em relação à definição dos trabalhos, utilizamos técnicas de análise cluster, agrupando os respondentes por suas respostas a estas variáveis. Os resultados mostraram a formaçáo de três grupos, os quais foram codificados pelos rótulos "legalistas", "sem opinião" e "estrategistas". Os primeiros usam fundamentalmente leis, decretos e normas como fonte de informaçáo; os segundos utilizam igualmente todas as fontes disponíveis; e os terceiros usam avaliaçóes de riscos da CGU, mapeamento de riscos do gestor, estratégias, objetivos e metas da unidade avaliada, estratégia da CGU e prioridades do gestor a ser avaliado.

Essas variáveis foram empregadas como explicativas em um modelo estatístico de regressão logística multinomial, semelhante a uma regressão logística, sendo que a variável resposta não é binária e contém mais de duas categorias/fatores. 
GRÁFICO 2

Comportamento dos clusters de participantes em função das escolhas sobre o grau de importância das fontes de informações

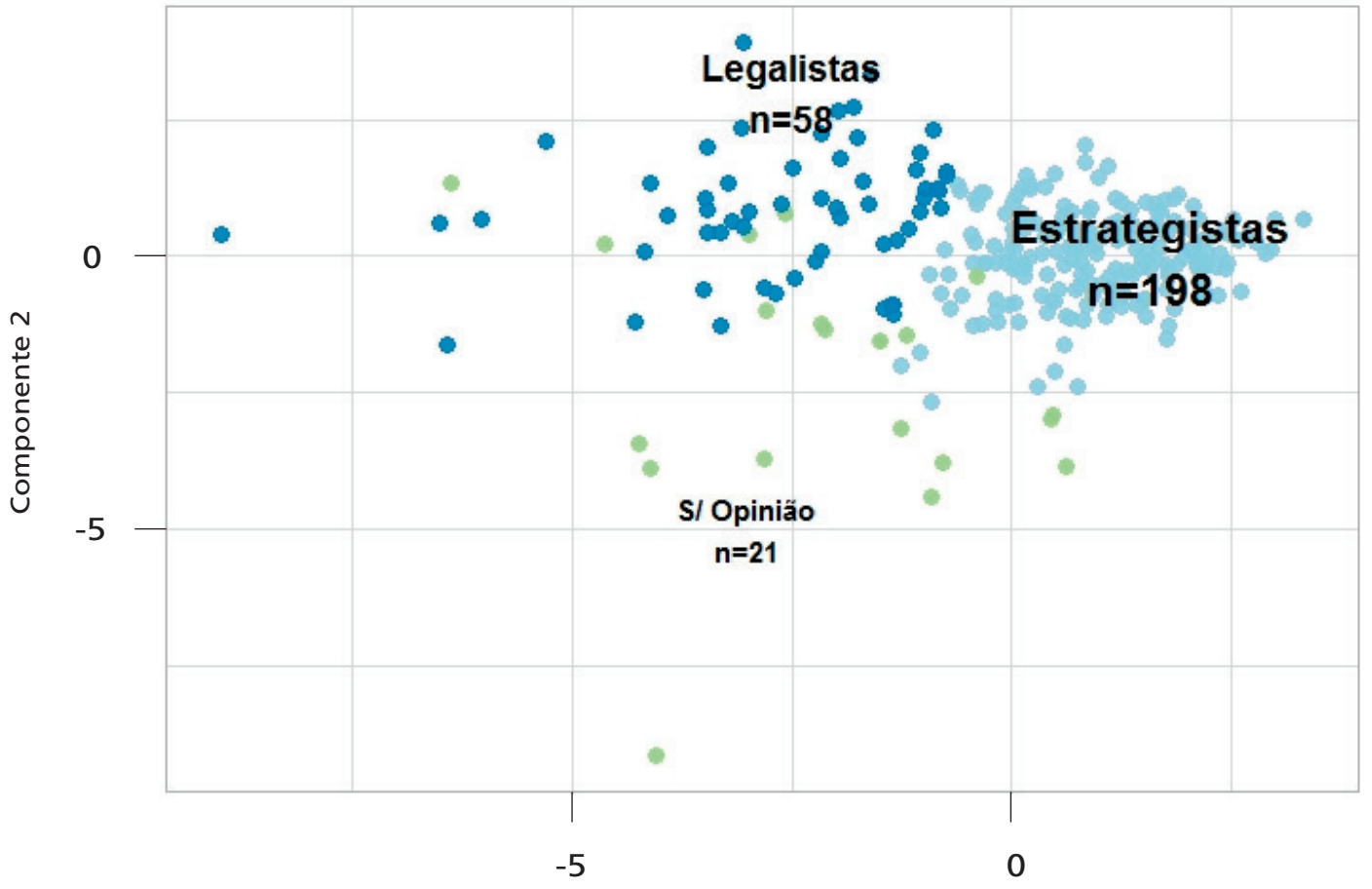

Componente 1
Grupos
Estrategistas
Legalistas
Sem opinião

Elaboração dos autores.

Obs.: Os eixos se referem aos dois primeiros componentes da análise fatorial e o gráfico mostra a relação de distâncias entre as categorias, com base nas respostas da survey.

O modelo estatístico de análise dos fatores determinantes das preferências de trabalhos dos servidores da CGU tem a seguinte forma funcional:

$$
y=\alpha+\sum_{i=1}^{n} \beta_{i} X 1+\gamma X 2+\epsilon
$$

Na equação (1), $\alpha$ é a constante, $X 1$ é a matriz de variáveis de controle que incluem o gênero, a formação acadêmica, a ocupação de funçáo comissionada e a lotação, além do cluster do grau de importância de utilização das fontes de informação, $X 2$ é a variável relativa ao IBD e $\varepsilon$ é o erro do modelo.

Os coeficientes $\beta$ e $\gamma$ foram estimados usando-se o método da máxima verossimilhança, utilizando-se uma regressão multinomial para a variável resposta $y$.

\section{RESULTADOS}

Em princípio, o estudo clareou que, conforme ensinamentos de Lindblom (1959), também no ambiente da auditoria interna governamental, o contexto das decisóes é rico e multifacetado, 
vinculado a redes de compromissos, interesses e poderes estruturados em torno de um conjunto de instituiçóes formais e informais.

Com base nos dados coletados, foi possível comprovar que $67 \%$ dos auditores internos da CGU preferem atuação didática com auditorias (51\% preferem avaliaçóes e $16 \%$ preferem consultorias) e 33\% preferem realizar atuação repressiva, com apuraçóes.

GRÁFICO 3

Tipos de serviços preferidos pelos auditores da CGU

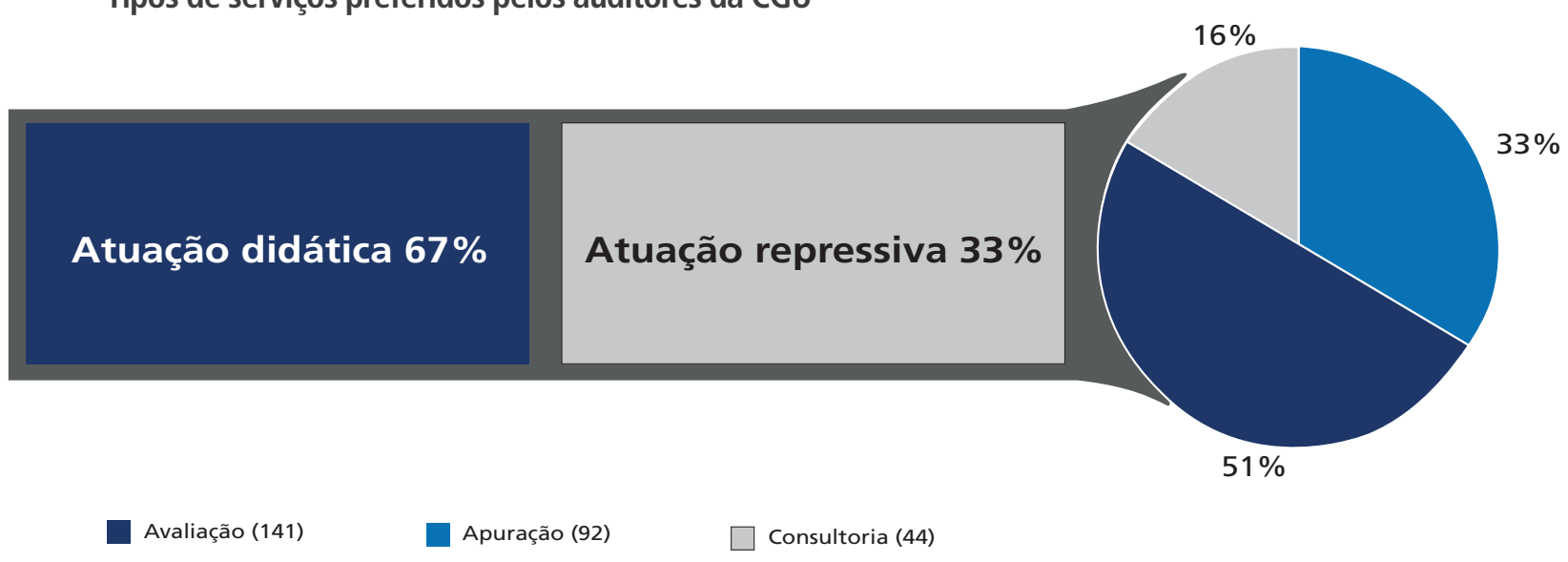

Elaboração dos autores.

Sob o ponto de vista estatístico, as estimativas do modelo dado na equaçáo 1 mostraram os coeficientes dispostos na tabela 1. A tabela mostra apenas as variáveis independentes que apresentaram significância estatística sobre as preferências dos auditores em relação aos serviços de apuração e avaliação.

A análise estatística dos dados coletados no survey indica os seguintes fatores que influenciam as escolhas dos auditores sobre a forma como atuam: auditores lotados em superintendências regionais da CGU têm 53,6\% a mais de chances de optar por realizar apuraçóes; há um acréscimo de 1,6\% nas chances de preferência dos auditores por apuraçóes a cada ano adicional de serviço; auditores do gênero masculino têm $23,1 \%$ a menos de chances de preferir um trabalho avaliativo; e auditores com pós-graduação ou escolaridade superior têm 34,8\% a menos de chances de preferir um trabalho avaliativo.

A análise do comportamento dos clusters $^{4}$ de participantes, em função das escolhas realizadas na questão sobre o grau de importância das diversas fontes de informaçóes para a definiçáo dos trabalhos, indica que os servidores "legalistas" têm 9,8\% a mais de chances de optar por apuraçóes.

A análise do IBD demonstra que, quando ele aumenta em 1 ponto (numa escala de 0 a 100), ocasiona um aumento de $2,1 \%$ nas chances de preferências por apuraçóes e de $0,8 \%$ nas chances de avaliaçóes, indicando que o uso de bases de dados está mais relacionado com apuraçóes.

4. Os clusters definidos foram: os "legalistas", que usam fundamentalmente leis, decretos e normas; os "sem opinião", que utilizam igualmente todas as fontes disponíveis; e os "estrategistas", que usam avaliações de riscos da CGU, mapeamento de riscos do gestor, estratégias, objetivos e metas da unidade avaliada, temas do Plano Tático da SFC e prioridades indicadas pelo gestor a ser avaliado. 
TABELA 1

Estimativas do modelo de regressão logística multinomial

\begin{tabular}{|c|c|c|}
\hline \multirow{2}{*}{ Variáveis explicativas } & \multicolumn{2}{|c|}{ Variável dependente } \\
\hline & Apuração (1) & Avaliação (2) \\
\hline \multicolumn{3}{|c|}{ Variáveis de controle } \\
\hline Idade (ano) & $\begin{array}{c}1.009 * * * \\
(0.034)\end{array}$ & $\begin{array}{c}1.045^{* * *} \\
(0.032)\end{array}$ \\
\hline Gênero: masculino & $\begin{array}{c}0.592 \\
(0.464)\end{array}$ & $\begin{array}{l}0.769^{*} \\
(0.438)\end{array}$ \\
\hline Escolaridade: pós & $\begin{array}{c}0.416 \\
(0.406)\end{array}$ & $\begin{array}{l}0.652^{*} \\
(0.387)\end{array}$ \\
\hline Função comissionada: sim & $\begin{array}{c}1.350^{* * *} \\
(0.482)\end{array}$ & $\begin{array}{c}1.302^{* * *} \\
(0.445)\end{array}$ \\
\hline Lotação: outros & $\begin{array}{c}1.239 \\
(0.803)\end{array}$ & $\begin{array}{c}0.459 \\
(0.804)\end{array}$ \\
\hline Lotação: Superintendência Regional da CGU & $\begin{array}{c}1.536^{* * *} \\
(0.456)\end{array}$ & $\begin{array}{c}0.992 * * \\
(0.407)\end{array}$ \\
\hline \multicolumn{3}{|c|}{ Variáveis independentes } \\
\hline IBD & $\begin{array}{c}1.021 * * * \\
(0.011)\end{array}$ & $\begin{array}{c}1.008^{* * *} \\
(0.011)\end{array}$ \\
\hline Grupo legalistas & $\begin{array}{c}1.098^{* *} \\
(0.449)\end{array}$ & $\begin{array}{c}0.514 \\
(0.441)\end{array}$ \\
\hline Grupo generalistas & $\begin{array}{c}0.647 \\
(0.657)\end{array}$ & $\begin{array}{c}0.458 \\
(0.606)\end{array}$ \\
\hline Constante & $\begin{array}{c}2.262^{* * *} \\
(0.606)\end{array}$ & $\begin{array}{c}5.279^{* * *} \\
(0.566)\end{array}$ \\
\hline $\mathrm{AIC}$ & 566.089 & 566.089 \\
\hline
\end{tabular}

Elaboração dos autores.

Obs.: 1. " $p<0.1 ;{ }^{* *} p<0.05 ;{ }^{* * *} p<0.01$; os erros-padrão estão entre parênteses. Os coeficientes foram exponenciados. A categoria "consultoria" da variável resposta foi utilizada como referência para as demais.

2. AIC - Akaike Information Criteria.

Das variáveis citadas anteriormente, os entrevistados trouxeram profunda reflexão sobre a influência da localização geográfica e do tempo de serviço do auditor. Aprofundamentos sobre as demais variáveis devem ser fruto de estudos futuros. Neste artigo, serão descritas as avaliaçóes empíricas relacionadas com o uso de informaçóes pelos auditores.

Os entrevistados ressaltaram que a atuação dos auditores se destaca por ser historicamente lastreada em evidências, sendo este um dos pilares da profissão.

Em relação às fontes de informação que baseiam os trabalhos, em uma visão geral, leis, decretos e normas são a principal fonte, ao lado de informaçóes sobre a materialidade ${ }^{5}$ das questóes auditadas e informaçóes produzidas pelas próprias unidades auditadas.

Por sua vez, os artigos científicos são considerados de menor relevância para os auditores. Sobre este achado, os entrevistados indicaram que algumas das políticas avaliadas contam com enorme gama de trabalhos acadêmicos já realizados, que podem ser aproveitados. No entanto, na visão dos entrevistados, alguns trabalhos acadêmicos possuem vieses que, se náo devidamente tratados, podem

5. Informações a respeito dos custos ou dos valores envolvidos nas diversas questões auditadas. 
comprometer a objetividade das auditorias. Quando aplicáveis, servem como inspiração metodológica ou confirmaçáo externa de dados.

Os entrevistados indicaram, ainda, que a seleção do tipo de fonte de informação a ser usada depende da maturidade da instituição e do setor avaliado. Órgãos e setores bem estruturados nacionalmente e internacionalmente contam com conhecimentos mais disseminados e, por este motivo, possibilitam a realização de benchmarkings, uso de informações vindas da academia ou de organismos internacionais. Em órgãos e setores em estruturação, existe menor grau de informação disponível. Nesse contexto, os auditores devem se basear em normativos e informaçóes fornecidas pela própria gestão, aproximando-se de avaliaçóes de conformidade.

Em relação à forma como as informaçóes são acessadas, as solicitaçóes de auditoria ${ }^{6}$ são os meios mais relevantes, seguidas de cruzamentos de bases de dados e pesquisas na internet. As menores relevâncias são atribuídas, respectivamente, a think tanks, às mídias sociais e aos grupos de interesse.

Em relação às bases de dados acessadas, em geral, as mais relevantes tratam sobre despesas do governo federal e sobre informaçóes cadastrais de pessoas e empresas.

\section{CONCLUSÕES}

A pesquisa permitiu tecer uma imagem do atual perfil da CGU em sua atuação na atividade de auditoria interna governamental. Observou-se que lotação (Brasília ou regionais), tempo de serviço, gênero e escolaridade do servidor podem influenciar a definiçáo do tipo de abordagem a ser adotada pelos auditores, se repressiva ou didática.

Em relação ao uso de informações, observou-se que consultas a bases de dados estão mais relacionadas com atuações repressivas. Além disso, constatou-se que artigos científicos possuem, em geral, baixa utilização pelos auditores e, quando aplicáveis, servem como inspiração metodológica e validação externa de dados.

A pesquisa contribui ao debate geral de políticas públicas baseadas em evidências (PPBEs), ao acrescentar dados sobre o uso de informaçóes por esse importante grupo de burocratas, que exerce relevante influência sobre as políticas públicas no Brasil.

\section{REFERÊNCIAS}

ALMEIDA, B. J. M. de. Adopted theories by the portuguese professionals to explain the auditing: empirical evidence. In: CONGRESSO INTERNACIONAL DE CONTABILIDADE E AUDITORIA, 14., 2013, Lisboa. Lisboa: [s.n.], 2013. Disponível em: <https://www.occ.pt/news/comcontabaudit/ pdf/10.pdf>. Acesso em: jan. 2020.

ARANTES, R. E. O controle interno como apoio à gestão dos órgãos públicos? Uma análise sob a perspectiva dos gestores federais. 2016. Dissertação (Mestrado) - Instituto de Pesquisa Econômica Aplicada, Brasília, 2016.

6. Meio de comunicação formal entre auditores e auditados para solicitação de informações. 
BENDOR, J. Bounded rationality and politics. [s.1.]: University of California Press, 2010.

CAMPANA, P. S. P. A cultura do medo na administração pública e a ineficiência gerada pelo atual sistema de controle. Revista de Direito, v. 9, n. 1, p. 189-216, 2017.

CGU - CONTROLADORIA-GERAL DA UNIÃO. CGU detalha novo referencial técnico de auditoria interna governamental. Portal da CGU, 26 mar. 2017. Disponível em: <https://www.gov. $\mathrm{br} / \mathrm{cgu} / \mathrm{pt}$-br/assuntos/noticias/2017/06/cgu-detalha-novo-referencial-tecnico-de-auditoria-internagovernamental>. Acesso em: 10 jun. 2019.

ENAP - ESCOLA NACIONAL DE ADMINISTRAÇÃO PÚBLICA. Capacidades estatais para produçáo de políticas públicas: resultados do survey sobre o serviço civil no Brasil. Brasília: Enap, 2018.

FILGUEIRAS, F. Burocracias do controle, controle da burocracia e accountability no Brasil. In: PIRES, R.; LOTTA, G.; OLIVEIRA, V. E. de. Burocracia e políticas públicas no Brasil - interseçóes analíticas. Brasília: [s.n.], 2018. cap. 14, p. 355-382.

GOMIDE, A. de Á.; PIRES, R. R. C. Capacidades estatais e democracia: arranjos institucionais de políticas públicas. Brasília: Ipea, 2014.

GREY, P. de F. C. A avaliação de impacto de políticas públicas e a contribuiçáo das auditorias internas dos institutos federais para a sua consecução: um estudo a partir da execução do PNAES no campus São Borja do Instituto Federal Farroupilha. 2018. Dissertação (Mestrado) - Universidade Federal do Pampa, São Borja, 2018.

HUMPHREY, C.; OWEN, D. Debating the 'power' of audit. International Journal of Auditing, v. 4, n. 1, p. 29-50, 2000. Disponível em: <https://doi.org/10.1111/1099-1123.00302>. Acesso em: dez. 2019.

IIA - INSTITUTE OF INTERNAL AUDITORS. Normas Internacionais para a Prática Profissional de Auditoria Interna. Lake Mary: IIA, 2017. p. 25.

LINDBLOM, C. The science of muddling through. Public Administration Review, v. 19, n. 2, p. 79-88, 1959.

NOGUEIRA, R. A.; GAETANI, F. A. Questão do controle no debate de governança pública. Boletim de Análise Político-Institucional, n. 19, p. 91-100, 2018.

OLIVEIRA, E. B. de J. O perfil da produção científica em auditoria governamental publicada em periódicos brasileiros no período de 2014 a 2017. 2018. Trabalho de Conclusão de Curso (Graduação) - Universidade Federal de Rondônia, Cacoal, 2018.

OLIVIERI, C. A atuação dos controles interno e externo ao Executivo como condicionante da execuçáo de investimento em infraestrutura no Brasil. Brasília: Ipea, 2016.

OLSEN, C.; GOLD, A. Future research directions at the intersection between cognitive neuroscience research and auditors' professional skepticism. Journal of Accounting Literature, v. 41, p. 127-141, 2018. Disponível em: <https://doi.org/10.1016/j.acclit.2018.03.006>.

PIRES, R. R. C. Estilos de implementação e resultados de políticas públicas: fiscais do trabalho e o cumprimento da Lei Trabalhista no Brasil. Dados, Rio de Janeiro, v. 52, n. 3, p. 735-769, 2009. 
POWER, M. The Audit Society. Rituals of Verification. Oxford: Oxford University Press, 1997. . The audit society - second thoughts. International Journal of Auditing, London, v. 4, n. 1, p. 111-119, 2000.

SOUZA, R. G. de. Auditoria interna: um panorama das pesquisas acadêmicas publicadas em periódicos e crongressos nacionais. 2017. Trabalho de Conclusão de Curso (Graduação) - Universidade Federal de Goiás, Goiania, 2017. 


\section{APÊNDICE}

\section{QUESTIONÁRIO DO SURVEY}

\section{QUADRO A.1}

\section{Perfil social do participante}

\begin{tabular}{|l|l|}
\hline \multicolumn{1}{|c|}{ Variável } & \multicolumn{1}{c|}{ Opções } \\
\hline Gênero & Masculino/feminino \\
\hline Ano de nascimento & De 1946 a 1989 \\
\hline Ano em que entrou na CGU & De 1973 a 2019 \\
\hline Maior nível de formação acadêmica & Ensino médio/graduação/especialização/mestrado/doutorado \\
\hline Exerce função comissionada? & Sim/não \\
\hline Qual função comissionada exerce? & DAS ou FCPE 1/DAS ou FCPE 2/DAS ou FCPE 3/DAS ou FCPE 4/DAS 5/outros \\
\hline $\begin{array}{l}\text { Qual a área de formação acadêmica } \\
\text { da sua maior titulação? }\end{array}$ & $\begin{array}{l}\text { Ciências agrárias (ex.: agronomia, veterinária, zootecnia etc.)/ciências biológicas (ex.: biologia, farmacologia, } \\
\text { genética etc.)/ciências da saúde (ex.: medicina, farmácia, odontologia, nutrição etc.)/ciências exatas e } \\
\text { da terra (ex.: física, matemática, química etc.)/ciências humanas (ex.: eduçãa, ciência política, história, } \\
\text { antropologia, filosofia, sociologia etc.)/ciências sociais aplicadas (ex.: administração, economia, arquitetura, } \\
\text { demografia, direito, comunicação, ciência da informação etc.)/engenharias (todas as engenharias, tais como } \\
\text { civil, elétrica, mecatrônica, naval etc.)/linguística, artes e letras/outros }\end{array}$ \\
\hline Lotação & Coordenação-Geral de auditoria na SFC/Superintendência Regional da CGU/outros \\
\hline
\end{tabular}

Elaboração dos autores.

Obs.: CGU - Controladoria-Geral da União; DAS - Direção e Assessoramento Superior; FCPE - Função Comissionada do Poder Executivo; SFC - Secretaria Federal de Controle Interno.

\section{QUADRO A.2}

\section{Pesquisa}

\begin{tabular}{|l|l|}
\hline \multicolumn{1}{|c|}{ Variável } & \multicolumn{1}{c|}{ Opçães } \\
\hline $\begin{array}{l}\text { Na sua opinião, qual é o potencial } \\
\text { de cada tipo de serviço de auditoria } \\
\text { interna governamental de adicionar } \\
\text { valor e melhorar as operações das } \\
\text { organizações públicas auditadas? }\end{array}$ & $\begin{array}{l}\text { Apuração/avaliação/consultoria. } \\
\text { (Escala Likert: muito alto/alto/nem alto nem baixo/baixo/muito baixo). }\end{array}$ \\
\hline $\begin{array}{l}\text { Imagine que foram disponibilizados } \\
\text { à sua escolha as seguintes opções de } \\
\text { possíveis próximos trabalhos. Você } \\
\text { deve selecionar apenas um. Qual } \\
\text { trabalho você executaria? }\end{array}$ & $\begin{array}{l}\text { Trabalho de apuração, indicado pelo Ministério Público Federal, de possível desvio de recursos } \\
\text { com fortes indícios de autoria por parte de autoridade de alto escalão de uma instituição pública } \\
\text { respeitada, de materialidade não alta, mas relevante. Caso comprovado, possui grande possibilidade de } \\
\text { virar notícia nacional. } \\
\text { Avaliação de governança, riscos e controles internos de política prioritária ao governo e à sociedade, com } \\
\text { alta materialidade. A avaliação possui o potencial de indicar caminhos para melhoria da eficiência e da } \\
\text { qualidade da entrega dos serviços públicos ao cidadão. }\end{array}$ \\
\hline $\begin{array}{l}\text { Consultoria, solicitada à CGU por ministro de pasta de grande importância política para o governo, para } \\
\text { atuar na facilitação do processo de formulação de política de abrangência nacional e de grande impacto na } \\
\text { vida cotidiana da sociedade como um todo. }\end{array}$ \\
\hline $\begin{array}{l}\text { Por qual motivo você selecionou a } \\
\text { opção anterior? }\end{array}$ & $\begin{array}{l}\text { Opção menos complexa/opção com maior possibilidade de agregação de valor/opção na qual possuo maior } \\
\text { experiência/opção na qual a CGU possui maior tradição/existe alguma pressão da CGU para realizar esse } \\
\text { tipo de trabalho/existe alguma pressão de meus colegas de trabalho para realizar esse tipo de trabalho/ } \\
\text { opção que representa a maior necessidade do governo federal atualmente/opção que é a que meus colegas } \\
\text { de trabalho se sentem mais confortáveis ao fazer/outros. }\end{array}$ \\
\hline
\end{tabular}


(Continuação)

\begin{tabular}{|c|c|}
\hline Variável & Opções \\
\hline $\begin{array}{l}\text { Indique o grau de influência dos } \\
\text { atores abaixo na definição dos } \\
\text { trabalhos que você realiza. }\end{array}$ & $\begin{array}{l}\text { Secretário federal de controle interno/equipe do Gabinete da SFC (antiga DC)/diretores de auditoria da } \\
\text { SFC/coordenadores-gerais de auditoria da SFC/superintendente de regional da CGU/chefe de divisão/chefe } \\
\text { de núcleo/gestores das unidades auditadas/colegas de trabalho e especialistas/minha própria decisão. } \\
\text { (Escala Likert: muito influente/influente/mais ou menos influente/de pouco influência/sem influência). }\end{array}$ \\
\hline $\begin{array}{l}\text { Na sua opinião, qual dos seguintes } \\
\text { possíveis resultados das auditorias é o } \\
\text { mais importante? }\end{array}$ & $\begin{array}{l}\text { Achados serem objeto de notícia nos meios de comunicação locais, nacionais e internacionais/os resultados } \\
\text { do trabalho renderem premiações dentro e fora da CGU/os resultados do trabalho renderem benefícios } \\
\text { financeiros e/ou não financeiros/a probabilidade de se desvendar esquema de desvio de recursos públicos/a } \\
\text { probabilidade de recomendar melhorias estruturantes às políticas públicas/outros. }\end{array}$ \\
\hline \multirow[t]{2}{*}{$\begin{array}{l}\text { Indique o grau de importância } \\
\text { dos seguintes tipos de dados e } \\
\text { informações para a definição dos } \\
\text { trabalhos que você realiza. }\end{array}$} & $\begin{array}{l}\text { Leis, decretos e normas/pareceres, notas técnicas e demais referenciais técnicos aplicáveis às unidades } \\
\text { auditadas/matérias ou notícias jornalísticas/percepções empíricas (ex.: conhecimento da equipe sobre o histórico } \\
\text { de certo gestor a ser auditado)/intuição pessoal/direcionamento dado pelo superior hierárquico/temas do Plano } \\
\text { Tático da SFC/mapeamento de riscos feito pelo gestor da unidade a ser auditada/avaliação de riscos feita pela } \\
\text { própria CGU/estratégias, objetivos e metas das unidades que serão auditadas/prioridades indicadas pelo gestor a } \\
\text { ser avaliado/materialidade dos recursos geridos pelas unidades a serem auditadas/artigos científicos. }\end{array}$ \\
\hline & (Escala Likert: muito importante/importante/mais ou menos importante/de pouca importância/sem importância). \\
\hline $\begin{array}{l}\text { Indique o grau de importância dos } \\
\text { seguintes meios de acesso aos dados } \\
\text { e informações que embasaram } \\
\text { a definição dos trabalhos que } \\
\text { você realiza. }\end{array}$ & $\begin{array}{l}\text { Pesquisa na internet/pesquisa na Base de Conhecimento da CGU/consulta a colegas de trabalho no meu } \\
\text { local de trabalho/consulta a especialistas (ex.: professores universitários, pesquisadores do Ipea, consultorias } \\
\text { especializadas)/respostas a solicitações de auditoria (SA)/reuniões com unidades gestoras/conferências } \\
\text { ou seminários/livros e artigos acadêmicos/índices e alertas de risco (ex.: Mara da DIE e Alice)/relatórios do } \\
\text { Macros/cruzamentos de bases de dados/denúncias/acórdãos, acordos firmados e indicações do } \\
\text { TCU/indicações de outras instituições de controle (ex.: MPF, TCE etc.)/acervo ou base de dados de livros, } \\
\text { artigos ou estudos acadêmicos (ex.: Google Scholar, Scielo, Proquest etc.)/estudos produzidos por institutos } \\
\text { de pesquisa governamentais (ex.: Ipea, IBGE, Enap etc.)/think tanks - laboratório de ideias, centro de } \\
\text { pensamento ou centro de reflexão/estudos de grupos de interesse (ex.: IBGC e consultorias especializadas)/ } \\
\text { notícias veiculadas na mídia normal/postagens nas mídias sociais. (Escala Likert: muito importante/ } \\
\text { importante/mais ou menos importante/de pouca importância/sem importância). }\end{array}$ \\
\hline & $\begin{array}{l}\text { Não usei bases de dados/abono salarial - pagamentos do benefício do abono salarial/Alice/Cadin - } \\
\text { Cadastro Informativo de Créditos não quitados do Setor Público Federal/CadUnico - Cadastro Único para } \\
\text { Programas Sociais do Governo Federal/Caged - Cadastro Geral de Empregados e Desempregados/CEIS - } \\
\text { Cadastro Nacional de Empresas Inidôneas e Suspensas/Cepim - Cadastro de Entidades Privadas Sem Fins } \\
\text { Lucrativos Impedidas/CES - Censo de Educação Superior/CNEP - Cadastro Nacional de Empresas } \\
\text { Punidas/CNES - Cadastro Nacional de Estabelecimentos de Saúde/CNIS - Cadastro Nacional de } \\
\text { Informações Sociais/CNPJ - Cadastro Nacional de Pessoa Jurídica/CPF - Cadastro Nacional de Pessoa Física. }\end{array}$ \\
\hline $\begin{array}{l}\text { Da lista de bases } \\
\text { indique aquelas qu } \\
\text { últimos dois anos } \\
\text { escopo ou da amo }\end{array}$ & $\begin{array}{l}\text { Dados de sistemas corporativos da CGU/DAP - Declaração de Aptidão ao Pronaf/ Garantia Safra - } \\
\text { beneficiários/IBGE - Cadastros do IBGE/Inep - microdados Censo Escolar - região Nordeste/MCMV - Minha Casa } \\
\text { Minha Vida/Ordens Bancárias - pagamentos realizados por OB/Portal da Transparência - banco de dados original } \\
\text { do ano de 2018/Programa Bolsa Família/ProJovem - Programa Nacional de Inclusão de Jovens/Prouni - Programa } \\
\text { Universidade para Todos/Rais - Relação Anual de Informaçõ̃es Sociais/Renach - Registro Nacional de Carteira de } \\
\text { Habilitação/Renavam - Registro Nacional de Veículos Automotores/RGP - Registro Geral da Pesca/Salic - dados } \\
\text { do Sistema de Apoio às Leis de Incentivo à Cultura/Seguro Defeso - beneficiários do Seguro Defeso/Seguro } \\
\text { Desemprego - beneficiários do Seguro Desemprego/Siafi/Tesouro Gerencial/Siapa - Sistema Integrado de } \\
\text { Administração Patrimonial/Siape - Sistema Integrado de Administraçãa de Pessoal/SIASG - Sistema Integrado } \\
\text { de Administração de Serviços Gerais/SIASUS - Sistema de Informaçôes Ambulatoriais do SUS/Siconv - Sistema } \\
\text { de Convênios/Sicor - Sistema de Operações do Crédito Rural e do Proagro/Siest - Sistema de Informações da } \\
\text { Estatais/Sigef - Sistema Integrado de Gestão Financeira (SigefWeb)/SIHSUS - Sistema de Informações } \\
\text { Hospitalares do SUS/Sipra - Sistema de Gerenciamento dos Projetos de Reforma Agrária/Sisben - Sistema de } \\
\text { Benefícios/Sisobi - Sistema de Controle de Óbitos/Sistema de Transferência de Informações/Sistema S - Base com } \\
\text { dados de licitações, pessoal, contratações, convênios, contabilidade das entidades do Sistema S/SPIUNET - Sistema } \\
\text { de Gestão dos Imóveis de Uso Especial da União/TSE - (prestação de contas de campanhas, candidatos, filiados a } \\
\text { partidos políticos)/Yggdrasil - banco com informações de vínculos/outros. }\end{array}$ \\
\hline $\begin{array}{l}\text { Considerando as bases de dados } \\
\text { acima indicadas, selecione abaixo o(s) } \\
\text { motivo(s) da escolha. }\end{array}$ & $\begin{array}{l}\text { Não consultei bases de dados/em função da qualidade dos registros/em função da facilidade de } \\
\text { utilização/em função da credibilidade da base/em função de experiência prévia/falta de opção/é a base que } \\
\text { está disponível/outros. }\end{array}$ \\
\hline
\end{tabular}

Elaboração dos autores.

Obs.: Alice - Análise de Licitações e Editais; TCU - Tribunal de Contas da União; MPF - Ministério Público Federal; TCE - Tribunal de Contas do Estado; IBGE - Instituto Brasileiro de Geografia e Estatística; Enap - Escola Nacional de Administração Pública. IBGC - Instituto Brasileiro de Governança Corporativa; Pronaf - Programa Nacional de Fortalecimento da Agricultura Familiar; Inep - Instituto Nacional de Estudos e Pesquisas Educacionais Anísio Teixeira; Siafi - Sistema Integrado de Administração Financeira do Governo Federal.; SUS - Sistema Único de Saúde; Mara da DIE - Mapeamento de Risco de Corrupção de Servidores Públicos Federais da Diretoria de Pesquisas e Informações Estratégicas; Macros - Sistema de apoio a atividades investigativas, de defesa do patrimônio público. Integra informações de diferentes bancos de dados governamentais e outras bases de dados abertas; DC - Diretoria de Planejamento e Coordenação das Ações de Controle, extinta em 2019. 